\title{
Bilateral Shoulder Combined with Unilateral Knee Dislocation After a Fall
}

\author{
Mehmet Ali Aslaner, Asliddin Ahmedali \\ Clinic of Emergency, Nevşehir State Hospital, Nevşehir, Turkey
}

A 54-year-old overweight woman presented to the emergency department (ED) complaining of severe pain and lack of movement in both shoulders and her left knee. Her medical history revealed that the episode began after slipping on the wet floor in the bathroom. The first dislocation of the knee joint occurred during the fall when she lost her balance, and the second occurred when she tried to use her arms to avoid hitting her head on the wet floor. There was no history of connective tissue disease, seizure, or prior dislocations. During clinical examination, there was no evidence of neurovascular deficit for upper extremities and left knee. Radiographs confirmed bilateral anterior glenohumeral dislocation combined with anterior left knee dislocation (Figure 1).

Bilateral anterior shoulder dislocations are reported less often. A recent review of 70 patients demonstrated that the causes of anterior injuries were trauma (50\%), muscle contractions (37\%) due to seizures or electrocution, and atraumatic events (13\%). Because of various etiologies, dislocation mechanisms are different.
Lever effect is a type of dislocation mechanism that forces abduction and external rotation of the arm. With the greater tuberosity pressing against the acromion, the humeral head is forced anteriorly out of the glenohumeral joint $(1,2)$. The patient, in this case, had low-energy trauma as well as left knee dislocation.

Complete dislocation of the knee causes devastating extremity injuries, particularly in the popliteal artery and peroneal nerve. The incidence of nerve and artery injury due to knee dislocation is $10 \%-40 \%$. Even worse, when a vascular injury secondary to a traumatic knee dislocation cannot be repaired within $8 \mathrm{~h}$, the amputation rate increases to nearly $85 \%$. Therefore, vascular assessment should include examination of both the dorsalis pedis and posterior tibial pulses, ankle-brachial index measurement, and computerized tomography (CT) angiography or arteriography. The patient had no clinical signs of vascular and nerve injury at the time of admission and observation, so she did not urgently need further radiological study such as CT angiography $(3,4)$.

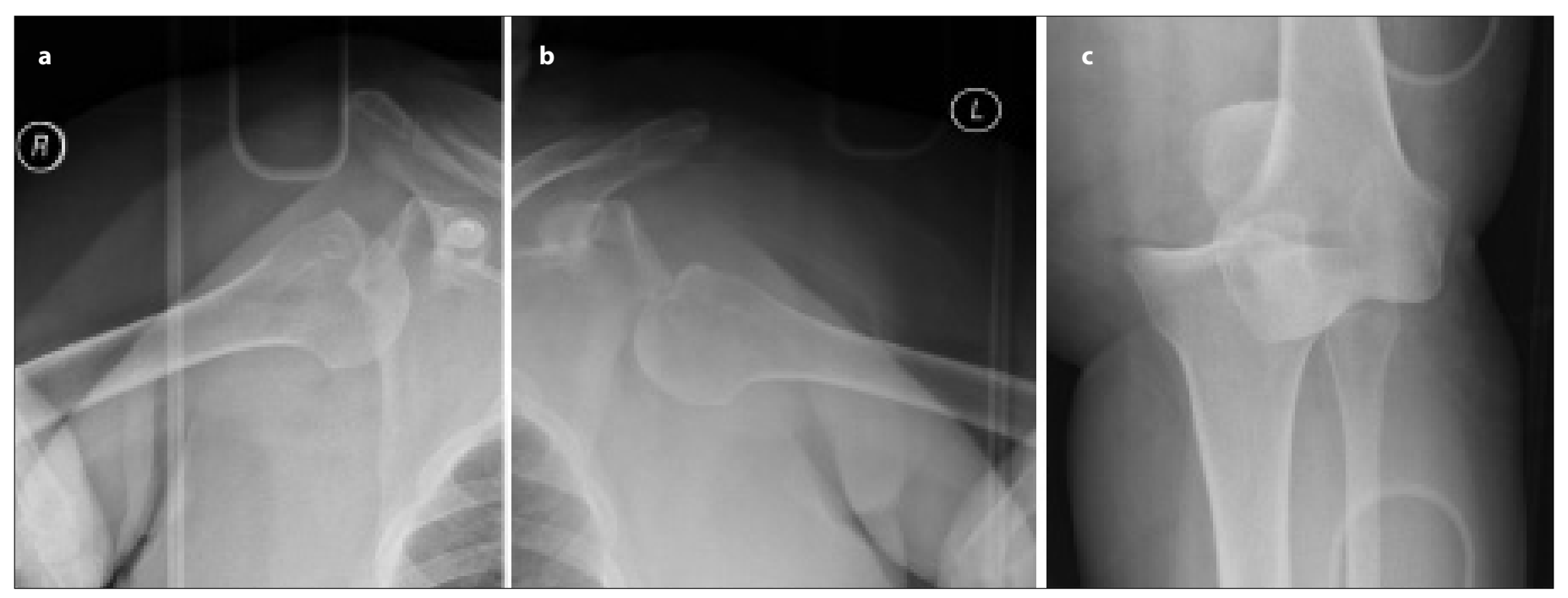

Figure 1. a-c. Anteroposterior X-ray shows bilateral shoulder and left knee dislocation

Correspondence to: Mehmet Ali Aslaner e-mail: maliaslaner@hotmail.com 
In conclusion, multiple large joint dislocations are extremely rare in the ED, and even in cases of low-energy trauma, such situations require urgent intervention, particularly in the case of knee dislocation.

Informed Consent: Written informed consent was obtained from the patient who participated in this case.

Peer-review: Externally peer-reviewed.

Conflict of Interest: No conflict of interest was declared by the authors.

Financial Disclosure: The authors declared that this study has received no financial support.

\section{References}

1. Ballesteros R, Benavente P, Bonsfills N, Chacon M, Garcia-Lazaro FJ. Bilateral anterior dislocation of the shoulder: review of seventy cases and proposal of a new etiological-mechanical classification. J Emerg Med 2013; 44: 269-79. [CrossRef]

2. Siwach $R$, Singh R, Rohilla R, Sangwan SS. Bilateral anterior dislocation of the shoulder-A case report and review of the literature. Injury Extra 2008; 39: 394-7. [CrossRef]

3. Peskun CJ, Levy BA, Fanelli GC, Stannard JP, Stuart MJ, MacDonald PB, et al. Diagnosis and management of knee dislocations. Phys Sportsmed 2010; 38: 101-11. [CrossRef]

4. Werner BC, Gwathmey FW, Jr., Higgins ST, Hart JM, Miller MD. Ultra-low velocity knee dislocations: patient characteristics, complications, and outcomes. Am J Sports Med 2014; 42: 358-63. [CrossRef] 